2. Конышева А.В. Организация самостоятельной работы учащихся по иностранному языку. - Спб.: КАРО, Мн.: Издательство «Четыре четверти», 2005. - 208 с.

3. Соловова Е.Н. Методика обучения иностранным языкам: продвинутый курс: пособие для студентов пед. вузов и учителей/ Е.Н. Соловова. - М.: АСТ: Астрель, 2008. - 272 с.

4. Полат, Е.С. Современные педагогические и информационные технологии в системе образования [Текст]: учеб. пособие для студентов высш. учеб. заведений / Е.С. Полат, М.Ю. Бухаркина. - М.: Издательский центр «Академия», 2007. - 368 с.

5. Щукин, А.Н. Современные интенсивные методы и технологии обучения иностранным языкам [Текст]: учебное пособие / А.Н. Щукин. -М.: Филоматис, 2008. - 180 с.

6. Халперн Д. Психология критического мышления. - СПб. : Питер, 2000. - 512 с.

7. https://www.un.org/sustainabledevelopment/ru/sustainable-development-goals.

8. https://www.futurelearn.com/courses/sustainability.

9. https://www.futurelearn.com/courses/organising-for-sustainable-development-goals.

\title{
Кирюшина О.В. \\ Специфика преподавания иностранного языка в контексте дистанционного образования
}

Нижнетагильский государственный соџиально-педагогический институт, филиал РГППУ

(Россия, Нижний Тагил)

doi: $10.18411 / l j-02-2021-136$

idsp: ljournal-02-2021-136

\section{Аннотация}

В статье рассматриваются преимущества и недостатки дистанционного формата обучения, проблемы и трудности его реализации, а также особенности обучения иностранному языку в удаленном режиме. Анализируется опыт работы по реализации дистанционного обучения у студентов высшего учебного заведения и даются рекомендации по итогам проведенной работы.

Ключевые слова: дистанционное образование, дистанционный формат обучения, модель преподавания иностранного языка, обучение аспектам иностранного языка, обучение видам речевой деятельности.

\section{Abstract}

The article discusses the advantages and disadvantages of the distance learning format, the problems and difficulties of its implementation, as well as the features of teaching a foreign language remotely. The experience of work on the implementation of distance learning among students of a higher educational institution is analyzed and recommendations are given based on the results of the work done.

Keywords: distance education, distance learning format, foreign language teaching model, teaching aspects of foreign language, teaching the types of speech activity.

В большинстве высших учебных заведений в последние годы преподавателей активно призывали разрабатывать дистанционные курсы, наполнять разные электронные оболочки, создавать электронную образовательную среду. Для этого организовывали курсы повышения квалификации по дистанционному образованию. Большинство преподавателей откликались, однако делалось это зачастую достаточно формально, потому что прежде всего не было понимания, зачем это нужно. Однако в связи с появлением коронавируса и ухудшением эпидемиологической обстановки в нашей стране и во всем мире потребовался резкий и неожиданный переход всей образовательной системы в дистанционный формат. Теперь уже ни у кого не осталось сомнений, что дистанционный формат обучения нужен. Да, он не может и не должен полностью заменить очный, но при качественной организации может стать важным дополнением к очному обучению и заменой очного формата в критической ситуации. 
По словам ученых и врачей данная пандемия, к сожалению, не последняя и далеко не самая опасная, назревают очаги новых инфекций. Потенциально возможны и другие веские причины для отказа от очной формы обучения. Поэтому дистанционный формат в сфере образования безусловно необходим, а это значит, что его нужно разрабатывать на совершенно ином качественном уровне.

Вслед за Ю. Ю. Котляренко под дистанционным (электронным) обучением мы понимаем процесс трансляции знаний в условиях территориальной удаленности с применением цифровых технологий [4, с. 77]. Современная система дистанционного образования должна обладать такими качествами, как открытость доступность, универсальность и возможность использования интегрированной базы данных [7, с. 124].

Однако, вынужденное дистанционное обучение весной 2020 года высветило для всего профессионального сообщества преподавателей и руководителей образовательных организаций множество проблем:

— технических (многие платформы просто не выдержали нагрузки);

- материальных (не все семьи обеспечены компьютерами и планшетами, особенно трудно было многодетным семьям);

- методологических (отсутствие четкой системы и концептуальной основы дистанционного образования как в стране в целом, так и в конкретных учебных заведениях, в частности);

- психологических (неготовность многих преподавателей к работе в новых условиях, неумение и нежелание пользоваться современными техническими средствами) и т. д.

Возникла также серьезная озабоченность проблемой здоровьесбережения. Ведь существенно возросло время, которое всем пришлось проводить у компьютера, а это дополнительная нагрузка на глаза и позвоночник, изоляция от общения с коллегами и сверстниками, что еще более усугубило психологически неблагоприятную ситуацию в обществе.

На наш взгляд, самой существенной причиной, почему возникли значительные трудности с реализацией дистанционного формата обучения весной 2020 года, было то, что большинство студентов совершенно не умеют и не желают работать самостоятельно: добывать знания, нести ответственность за свою учебу, выстраивать собственную образовательную траекторию. Мы постоянно делаем акцент на концепции непрерывного образования, реализуем современные стандарты образования, построенные на отказе от готового знания и развитии у обучающихся собственной познавательной активности, но весенняя ситуация 2020 года отчетливо продемонстрировала всем нам, что бОльшая часть всех этих благих идей остается на бумаге, а в реальности наша образовательная система по-прежнему заточена под передачу от преподавателя студентам некой сакральной истины. И никак и ничем преподавателя не заменить. Именно поэтому дистанционный формат весной 2020 года вызвал взрыв в обществе, в соцсетях, привел к массовому недовольству со всех сторон: преподавателей, студентов, родителей. Это было что-то совершенно новое и непривычное, что, как правило, сначала всегда отвергается обществом.

Однако, у дистанционного формата обучения, как и у любого явления действительности, есть свои очевидные плюсы и минусы. К плюсам можно отнести следующие моменты:

— обучение в целом становится более гибким: обучающийся сам может регулировать время на выполнение задания, темп его выполнения, сам организует рабочее место с точки зрения индивидуального комфорта;

- отсутствие временных и финансовых затрат на дорогу до учебного заведения, питание и т. д. 
- более индивидуализированный характер обучения, возможность создания индивидуального графика обучения, адаптивных учебных материалов и методических рекомендаций, возможность укорить процесс получения образования;

— возможность при обучении на различных электронных платформах собрать так называемую учебную аналитику и отследить индивидуальный прогресс в обучении: сколько времени и с какой периодичностью обучающийся затрачивает на тот или иной вид задания, возвращается ли к заданию и т. д.

Исследователи отмечают также возможность обучения сразу в нескольких учебных заведениях одновременно [7, с. 125], обеспечение высокой степени наглядности материалов за счет графического контента и постоянной визуализации материала) [1, с. 56], возможность удаленного обучения иностранцев и лиц с ОВ3, свободный доступ к базам данным и информационным ресурсам, возможность быстрого обмена информацией и удобное ведения личных дел обучающихся [2, с. 97].

В то же время можно отметить и определенные минусы дистанционного обучения:

- технические неполадки в сети или перебои с электричеством могут свести на нет даже самый хорошо разработанное занятие;

- увеличивается нагрузка на преподавателей и студентов;

- современные студенты и без того проводят огромное количество времени в виртуальном мире;

— обучение в целом социальной природы, а не технической.

Кроме того, исследователи указывают на отсутствие эмоциональной связи между преподавателем и студентом, невозможность организовать творческую среду обучения, высокую трудоемкость разработки курсов дистанционного обучения [5, с. 10] и др.

Концентрация на плюсах дистанционного формата обучения и сведение к минимуму его недостатков позволит, на наш взгляд, выстроить качественный процесс обучения любой дисциплине и в любом учебном заведении.

Что касается модели преподавания иностранного языка в контексте дистанционного образования, то она, не меняясь содержательно, претерпевает существенные изменения по форме. Кратко проанализируем специфику обучения иностранному языку в дистанционном формате.

Исследователи отмечают, что при дистанционном обучении иностранному языку проще выстраивать индивидуальную образовательную траекторию, использовать аутентичные материалы и добиваться погружения в языковую среду. Кроме того, студент видит материал всего курса, его структуру и может правильно распределить свою нагрузку, спланировать работу [6, с. 105].

Дистанционный формат обучения иностранному языку располагает большим арсеналом технических возможностей для обеспечения синхронного удаленного взаимодействия преподавателя и студентов: интерактивные видеолекции, семинарские онлайн-занятия, видеоконференции, вебинары, учебные чат-занятия и др. [3, с. 89]. Западные исследователи отмечают, что использование тех или иных электронных средств и платформ сильно отличается в зависимости от учебного заведения и еще больше в зависимости от конкретной учебной дисциплины, что, как правило, приводит к ситуации, когда каждое подразделение определённого учебного заведения накапливает свой собственный опыт дистанционного обучения [8, с. 7].

На нашем факультете (факультет филологии и межкультурной коммуникации) удаленное обучение реализовывалось на платформах skype, zoom и moodle. При этом 
дистанционный формат по-разному отразился на различных аспектах иностранного языка и видах речевой деятельности.

Как известно, обучение фонетическому аспекту иностранного языка предполагает формирование звуко-произносительных и ритмико-интонационных навыков и постоянную работу над развитием фонематического слуха обучающихся. Обучение данному аспекту языка дистанционный формат обучения не слишком осложнил. Стихи, скороговорки, диалоги, работа со звуками и интонемами, как и в очном режиме, абсолютно доступны для работы в дистанционном формате. В некотором роде даже лучше и отчетливее слышны огрехи каждого при воспроизведении учебного материала или, например, при проверке техники чтения у начинающих. На любой электронной платформе можно выкладывать треки для развития фонематического слуха, звукобуквенных соотношений. Обучающиеся пишут в чате после прослушивания, как поняли, а преподаватель контролирует.

Лексический аспект иностранного языка подразумевает формирование рецептивных и продуктивных лексических навыков и различные этапы работы над лексикой - от семантизации до закрепления и повторения. Все эти этапы осложняются в дистанционном формате. Для семантизации лексики, конечно, можно просто пользоваться переводом, однако, данный способ, будучи самым примитивным, должен использоваться только в крайнем случае. Больше следует семантизировать через наглядность, контекст, дефиниции, синонимы, антонимы и т. д., чтобы развивать механизм языковой догадки. Вот как раз семантизация с помощью наглядности уже требует подготовки презентаций и демонстрации экрана, то есть дополнительных затрат сил и времени. Многие приемы работы по закреплению лексики - разгадывание кроссвордов в паре, лексические игры, которые мы обычно часто практикуем в учебной аудитории, оказались труднореализуемыми или совсем невозможными. В целом данный аспект показался самым неудобным для реализации в дистанционном формате.

Обучение грамматическому аспекту иностранного языка предполагает формирование рецептивных и продуктивных грамматических навыков. Обучение грамматике протекало абсолютно в том же ключе, что и очно: объяснение правил с примерами, схемы на доске перед камерой или в чате, выполнение тренировочных упражнений на закрепление, выход в речь на основе собственно коммуникативных упражнений. Но следует отметить, что если организовывать обучение грамматике индуктивным путем, когда обучающиеся должны сами вывести правила, то требуются презентации, особая подготовка и будет крайне сложно, если вообще возможно, удаленно организовать групповую работу.

Некоторые преподаватели попытались заменить свои объяснения грамматических правил найденными роликами на YouTube, однако, по нашему мнению, большинство из них довольно низкого качества. Лучше самому записывать такие ролики и выкладывать на свой канал, это совершенно бесплатно и очень удобно. И это совсем не бесполезный труд, как может показаться: всегда есть студенты, которые не поняли объяснение в аудитории, те, кто проболел, пропустил занятие по иной причине. Чтобы многократно не объяснять и не тратить время на уроке - можно просто давать ссылку на свой канал. Это будет легко и практично.

Кроме того, можно воспользоваться надежными и проверенными сайтами, где есть и правила, и примеры, и упражнения, и тесты для самостоятельной работы с ключами. Это хорошее дополнение к обучению иноязычной грамматике. Но сайты должны быть действительно надежными и лучше аутентичными. Потому что сейчас в сети Интернет можно найти много так называемых учебных сайтов, где представлено большое количество абсолютно ошибочной информации.

Обучение иноязычному чтению предполагает обучение технике чтения и собственно смысловому чтению, а также работу над разными видами чтения. Особой разницы в обучении чтению очно и дистанционно нами не было установлено. Кроме обычных учебных материалов, можно использовать хорошие сайты с аутентичными 
текстами для разных уровней владения иностранным языком, с небольшими тестами к ним на проверку понимания. Была возможность, например, на экзамене дать каждому свой текст и неожиданно, по ссылке, чтобы не было возможности что-то заранее подготовить.

Обучение иноязычному письму предполагает обучение технике письма и собственно письменной речи. Этот вид речевой деятельности совершенно не пострадал в обучающем формате. Можно было точно так же писать эссе, темы, проверять и корректировать, пересылать по электронной почте или выкладывать и контролировать на платформе moodle. Но проблема возникла там, где это должно было стать контрольным мероприятием: например, итоговое изложение, которое является частью экзамена. Удаленное его написание не представляется возможным ввиду того, что нет контроля за степенью самостоятельности выполнения данного вида задания (даже при условии включенных камер).

Обучение иноязычному аудированию предполагает развитие аудитивной компетенции обучающихся и работу над разными видами аудирования. В дистанционном формате существует много плюсов для детального аудирования (потому что студенты могли прослушивать аудиотексты нужное им количество раз, вместо привычных двух), но минусы для глобального аудирования, по той же самой причине. Поэтому если требовалось именно понимание общей информации с первого или со второго раза, то аудиотекст следует выкладывать непосредственно перед занятием, а не заранее. В обучении иноязычному аудированию можно также воспользоваться сайтами, где представлены многочисленные аудиокниги на иностранном языке для разного уровня владения языком.

Обучение говорению предполагает развитие умений диалогической и монологической речи. В условиях дистанционного обучения снижается качество обучения диалогической речи, но не так сильно страдает речь монологическая. Самым трудным показалось то, что легко было добиться взаимодействия «преподавательстудент», но не взаимодействия «студент-студент». Такие традиционные задания, как составление диалогов и их разыгрывание по ролям оказались неэффективными. Технически это можно было осуществить, но не было ощущения присутствия, естественного общения, истинной коммуникации.

В монологической речи приходилось реализовывать больше спонтанной речи, неподготовленной, потому что студенты все подготовленное могли просто считывать. А вот внезапные коммуникативные ситуации и неожиданные вопросы сразу показывали, как выучен материал, как студенты готовы выражать свои мысли средствами иностранного языка.

При осуществлении контроля возникло много проблем. И дело даже не в том, что у студентов появилось больше способов хитрить, списывать и т. д. А в том, что просто стали невозможными некоторые существенные формы контроля при обучении языку. Например, словарные диктанты. Конечно, можно устно опросить лексические единицы, но так не проверишь орфографию. Совершенно невозможной стала работа у доски. Письменные формы контроля, как уже отмечалось ранее, стали более проблематичными в целом, а просто тестами глубоко владение иностранным языком не проверить. Это слишком поверхностная форма контроля, когда можно замерить лишь знание лексических единиц и грамматических конструкций и то, большей частью, в рецептивном виде. Владение видами речевой деятельности (говорением, аудированием, чтением и письмом) проверить с помощью тестов значительно сложнее. Кроме того, в условиях дистанционного обучения иногда вообще отсутствует возможность проверить, кто на самом деле написал тут или иную работу. Поэтому аспект контроля в дистанционном формате весьма проблематичен и требует особой разработки.

Bblводbl:

1. Н Наш взгляд, даже реализуя очную форму обучения, следует отдельные аспекты обучения иностранному языку постоянно выносить на дистанционный формат, 
чтобы сделать это рутинным и привычным, повышать качество обучения за счет сочетания обеих форм и сделать систему образования в целом более гибкой, готовой в любой момент перейти на один из форматов обучения или их сочетать (смешанное обучение).

2. Необходимо преодолевать внутренние барьеры против современных технологий и создавать собственную электронную обучающую базу: видеолекции, учебные ролики на YouTube, презентации по темам. Весь этот материал можно использовать при любой форме работы, он всегда найдет применение, особенно с отстающими студентами, с часто болеющими, со студентами с ОВ3 и т. д. А кроме того - в частной практике, для тех, кто занимается репетиторством. Дистанционная школа позволяет научиться проводить групповые занятия в удаленном режиме, демонстрирует, как можно дальше развиваться в этом направлении. А именно за удаленным образованием будущее, как бы мы этому внутренне не сопротивлялись. И у него действительно много плюсов, много удобств, просто нужно научиться работать по-новому.

3. Следует осознать для себя и разработать собственную целостную модель обучения иностранному языку в дистанционном формате: по всем аспектам языка (лексика, фонетика, грамматика) и видам речевой деятельности (чтение, аудирование, письмо и говорение). Чтобы обучение не было фрагментарным и обрывочным, хаотичным, а стало системным, продуманным на всех этапах: от постановки учебных задач до контрольных мероприятий. У каждого из нас эта модель будет своя, авторская, здесь нет универсальных рецептов. Но каждый преподаватель в состоянии эту модель разработать и содержательно ее наполнить. Единожды ее разработав, мы можем дальше долго ей пользоваться, совершенствуя и дополняя ее по ходу учебного процесса.

4. Особое внимание следует уделить формированию $u$ развитию познавательной самостоятельности и активности обучающихся. Следует, наконец, не на словах, а на деле уходить от фронтального обучения к групповому и индивидуальному, от передачи готового знания к самостоятельному его добыванию, от объяснительно-иллюстративных методов обучения к проблемным, активным и интерактивным, от позиции «к группе с ответом» к позиции «к группе с вопросом», от школы памяти к школе мышления. Тогда мы действительно будем воспитывать принципиально иной тип личности: активный, самостоятельный, готовый к разным вызовам будущего, к решению самых разнообразных проблем. Тогда нам будет не страшен ни дистанционный формат обучения, ни новая пандемия.

$$
* * *
$$

1. Бондаренко Т. Г., Колмаков В. В. Дистанционное обучение как активная образовательная технология: оценка целесообразности внедрения / Т. Г. Бондаренко // Азимут научных исследований: педагогика и психология. - 2018. - № 3(24). - С. 53-56.

2. Гагарина Л. Г., Колдаев В. Д. Инновационные образовательные технологии дистанционного обучения / Л. Г. Гагарина // Экономические и социально-гуманитарные исследования. - 2018. - № 4(20). - С. 96-102.

3. Дахин Д. В., Шилова О. И. Использование технологий дистанционного обучения в учебном процессе вуза при подготовке студентов профиля «Технология» / Д. В. Дахин // Международный электронный научный журнал. - 2018. - 2(32). - С. 87-90.

4. Котляренко Ю. Ю., Симонова О. Б. Электронное обучение или дистанционное обучение (эмпирическое исследование на примере иностранного языка) / Ю.Ю. Котляренко, О.Б. Симонова // Казанский педагогический журнал. - 2020. - № 3 (140). - С. 75-83.

5. Кузьмина Л. В. Преимущества и недостатки дистанционного обучения / Л. В. Кузьмина // Вестник Московского университета МВД России. - 2012. - № 1. - С. 8-10.

6. Пашина А. В. Достоинства и недостатки дистанционного обучения ан-глийскому языку в техническом вузе / А. В. Пашина // Электронный научный журнал. - 2020. - № 5 (34). - С. 103-105.

7. Царев В. И. Преимущества дистанционного обучения / В. Царев // Выс-шее образование в России. - № 4. - 2000. - C. 124-126.

8. Persike, M., Friedrich, J.-F. Lernen mit digitalen Medien aus Studierendenperspektive. Arbeitspapier Nr. 17. - März 2016. - Berlin. - 47 S. 